\title{
Antitranspirants: An Effective Approach to Mitigate the Stress in Field Crops
}

\author{
Vishal Guleria $^{1 *}$ and Shweta ${ }^{2}$ \\ ${ }^{1}$ Lovely Professional University, Jalandhar, Punjab, India, 144411 \\ ${ }^{2}$ Chaudhary Sarwan Kumar Himachal Pradesh Krishi Vishvavidyala, \\ Palampur, 176062, India \\ *Corresponding author
}

\section{A B S T R A C T}

\section{Keywords}

Transpiration suppressant agents, Photosynthesis, Water stress, Yield

Article Info

\section{Accepted:}

15 April 2020 Available Online: 10 May 2020
Antitranspirants are the compounds or the substances applied to the leaves of the plants for the purpose of reducing water loss (transpiration) without causing a momentous change in the various important processes of the plant such as growth and photosynthesis. Antitranspirants are generally classified into four distinct categories viz., stomatal closing type, filmforming type, reflecting type and growth retardant. Antitranspirants application in cereal crops play very immense role as they are known to be involved in retaining water in the soil profile which helps to reduce water stress and improved the water holding capacity significantly. It also results in increased photosynthesis rate, chlorophyll content, stomatal resistance, protein content, oil content, proline content and also improved the activity of antioxidant enzymes (SOD, POD and GR). Moreover, treatment with these antitranspirants leads to tremendous increase in seed germination, growth rate and most importantly yield of grain and yield contributing characters in different cereal crops.

\section{Introduction}

Antitranspirants are the chemical compound which results in declining the respiration rate from the leaves of the plants by reducing the number and size of the stomata and eventually hardening them to stress (Ahmed et al., 2014; El Khawaga, 2013). They are also known as transpiration suppressant agents. Based on the mode of their action, they are categorised into: stomatal closing type (Phenyl mercuric acetate and ABA), film forming type (Mobileaf, hexadeconol and silicon), reflectant type (Kaolin, calcium bicarbonate and China clay) and growth retardants (cycocel). In the field crops, the practical use of antitranspirants involves decreasing the water loss from the leaves by reducing the 
size and number of stomatal opening and therefore decreasing the rate of diffusion of moisture vapour. It is very important to control the loss of the water from the plant because only a very small amount of water taken up by the roots, out of which $98 \%$ is lost to the atmosphere through transpiration. Antitranspirants helps in minimising these losses to some extent. The role of antitranspirants increases in dryland agriculture where availability of water is very less and the temperature is very high which promotes the rate of transpiration. Antitranspirants reduces the transpirational losses by increasing the leaf resistance to the water vapour transfer by covering of stomata (stomatal antitranspirants). Leaf reflectant reduces the water losses by reflecting the large amount of radiation, they decline the leaf temperature and vapour pressure gradient from leaf to the atmosphere and thus reduce rate of transpiration. Antitranspirants also control the water vapour losses by retarded the root and shoot growth and thus allow the plant to resist the drought (Growth retardant). Film forming antitranspirants produce an external physical barrier outside the stomatal opening to retard the runaway of the water vapour through stomatal opening. Antitranspirants minimises transpirational losses, so that limited amount of the soil moisture can be utilised by the plants for completing the life cycle of the crop plant. Antitranspirants along with slowing down the rate of transpiration also reduces the photosynthesis efficiency of the crop plant due to less uptake of the carbon dioxide through the narrowed aperture of the stomata, comparatively less permeability of carbon dioxide through the film and rise in leaf temperature. Moreover, most importantly use of antitranspirants results in reducing water and drought stress, retaining more water in the leaves and therefore tremendously improved the water use efficiency (WUE) of the plants.

\section{Effects of antitranspirants in field crops}

\section{Antitranspirants in wheat}

In wheat cultivar DWD-1006, irrigation, mulch and antitranspirant application were found to improvise the growth, yield and yield contributing attributes and cost of cultivation. Five irrigations at different critical stages increased the various growth parameters, mulched treatment provide highest total dry matter production per plant and treatment with antitranspirant, kaolin along with five irrigations were found to increase the dry matter accumulation, grain yield and also offers highest gross return and cost of cultivation (Brahma et al., 2007). Antitranspirant treatment with fulvic acid @320ppm spray in wheat (cv. Sakha 93) were reported to increase various vegetative parameters, physiological properties, anatomical structure of leaf, grain yield, concentration of photosynthetic pigments (chlorophyll a, b and carotenoids) and photochemical activities in leaves under water defict conditions (Desoky et al., 2013). At drought stressed stage, application of filmforming type antitranspirants in wheat were found to augmented the yield of grain by efficiently maintaining maximum grain number and increasing the grain setting. It also decreased the transpiration rate at drought sensitive stage and mitigating the unfavourable effects of drought in late-season wheat (Abdullah et al., 2015). Exogenous and combined application of both antitranspirants, ABA (at the early grain fill stage) and fulvic acid (at the heading stage) were found to improvise the performance of wheat grown in winter season. This treatment results in enhancing the biomass distribution both above and below ground which in turn also increased the water use efficiency, harvest index of crop and significantly increased the total assimilate ratio (TRA) and grain yield water deficient conditions (Zhang et al., 
2016). It was observed that variety, Raj 3077 with $100 \%$ RDF and antitranspirant application like cycocel @ 1000 ppm in wheat crop significantly augmented highest growth parameters, yield and yield attributing traits and in turn also offer maximum nutrient concentration and nutrient uptake (especially nitrogen and phosphorus) (Balwan et al., 2017). Under water deficient conditions, in wheat variety HD-2967, antitranspirants like pusa hydrogel $(100 \%)$ and chitosan $(100 \%)$ along with $60 \%$ irrigation were found effective to boost the growth, reproductive parameters, yield and yield attributing characters as pusa hydrogel can retain larger quantity of water and chitosan were known to reduce the transpirational rate (Burondkar et al., 2018). Maximum crop growth, yield and yield contributing traits were reported to be enhanced by the application of antitranspirants, hydrogel @ 100\% and chitosan@100\% under adverse climatic condition of water stress in wheat, also cope up the water stress to a larger extent. These antitranspirants viz., hydrogel and chitosan were found to retain water in the soil and reduce the water loss through stomata (Reddy et al., 2018). Antitranspirants, such as kaolin and potassium sulfhate were found to improvise the physiological, biochemical, yield and yield contributing aspects of wheat plant especially by alleviating the water stress and by reducing the extent of transpiration. Foliar application of wheat cultivar Gimeza 7 with antitranspirants, kaolin (3 or 6\%) and potassium sulfate $(100$ and $200 \mathrm{mg} / \mathrm{ml})$ leads an tremendous increase in the growth rate, yield components and biochemical aspects like carbohydrates, antioxidant enzymes, photosynthetic pigments and mineral contents (N,P,K, Ca) (Abdallah et al., 2019).

\section{Antitranspirants in maize}

Antitranspirant application with alachlor @ $20 \mathrm{mg} /$ litre in maize plants was reported to be most effective in reducing the rate of transpiration and partially hindered the stomatal opening. This treatment with antitranspirant also results in the higher rate of photosynthesis and in turn leads to an increased growth rate and yield (Santakumari et al., 1977). Exogenous application of antitranspirants viz., salicylic acid $(0.5 \mathrm{Mm})$ and paclobutrazol $(50 \mathrm{ppm})$ were found to enhance the vegetative characters such as total dry weight, leaf area index, growth rate and weight of 1000 seeds of the maize plants under water stress condition. It also results in marvellous increase in the growth rate, biological yield and yield contributing traits (Bayat and Sepehri, 2012). Antitranspirants treatment with salicylic acid @200 mg/l, vapour gard @ 15 ml/l, kaolin clay @ 200 mg/l and leaf sil @ 15 ml/l were reported to alleviate the transpiration loss during water stress condition in maize plants. It also results in augmented the various growth traits viz., number of leaves, leaf area, leaf area index, plant dry matter, crop growth and also increased the yield of the plants (Ulameer and Ahmed, 2018). Combined application of soil superabsorbent $\left(45 \mathrm{~kg} \quad \mathrm{hm}^{-2}\right)$ and antitranspirant, fulvic acid solution $\left(2 \mathrm{~g} \mathrm{~L}^{-1}\right)$ were reported to improvise the rate of photosynthesis, chlorophyll contents and water use efficiency (WUE) in maize plants under low rainfall conditions. Collective use of these two leads to an increase in grain yield by $20 \%$ and water use efficiency by $26 \%$ by boosting the photosynthesis and increasing kernel number (Yang et al., 2019a). Coapplication of superabsorbent polymer (SAP $@ 4.5 \mathrm{~g} \mathrm{~m}^{-2}$ ) and antitranspirant, fulvic acid solution (FA @2 $\mathrm{g}^{\mathrm{L}-1}$ ) were reported to increase grain yield of maize significantly under water deficient conditions. Moreover, this treatment also leads to a greater improvement in net rate of photosynthesis, chlorophyll content, fluorescent parameters, but also maintains highest proline content in leaf which helps to further alleviate the 
adverse effects of less water storage specifically on maize growth (Yang et al., 2019b).

\section{Antitranspirants in barley}

Pre and post inoculation sprays of filmforming type of antitranspirants viz., $\mathrm{Nu}$ - film $\mathrm{P}$, emerald and vapor gard results in greater decline in powdery mildew infection of barley seedlings, significantly. For better results, mixture of $2 \%$ vapor gard along with $1 \mathrm{Mm}$ alpha- difluoro methylornithine (DFMO) were found to be the best against the fungus and applied before one day to inoculation with the fungus (Walters, 1992). Spraying of barley cv. Karoon and bean cv. Talash plants with antitranspirants, like phenyl mercuric acetate (PMA) at the rate of $100-750 \mathrm{uM}$ for barley and 100Um for bean under saline conditions results in tremendous increase in both fresh and dry weight of the plants, also increase in $\mathrm{K} / \mathrm{Na}$ ratio in shoots, improves water balance and photosynthetic efficiency (Abbaspour and Khold, 2002). In barley, application with three film forming type of antitranspirants such as ethokem, bond and vapor gard were found effective to control the powdery mildew fungus Blumeria graminis $\mathrm{f}$. sp. hordei by reducing the conidia germination and also reduced the succeeding formation of appressoria and haustoria, when applied as pre or post inoculation treatments (Sutherland and Walters, 2002). Under glasshouse condition, antitranspirants sprayed at two different concentrations @ 7\% and $10 \%$ at tillering and stem elongation stages results in reducing cuticle as well as stomatal transpiration, thus decreased plant stress and curtail plant stress in both barley and durum wheat grown under water deficient conditions. Moreover, it saves the more water content in foliage, improves plant water stress and increases the photosynthetic activity (Ouerghi et al., 2010). Foliar treatment with antitranspirant, vapor gard increased the leaf water potential and photosynthetic rate of durum wheat and barley significantly, which were grown in water defict conditions under glasshouse. It reduces the water stress, combat the water stress condition and increased the yield of cereal crops enormously (Ouerghi et al., 2014). Foliar application of antitranspirants, salicylic acid and magnesium carbonate significantly reduced the adverse effect of water stress in barley. This application with antitranspirants also showed positive effect in improvement of relative water content, plant pigments, nutrient content, proline accumulation and also improved the activity of antioxidant enzymes such as catalase (CAT), peroxidase (POD) and glutathione reductase (GR) which helps to mitigate the water defict conditions (Hellal et al., 2020).

\section{Antitranspirants in soybean}

Foliar application of antitranspirants, applied at 60 days after planting i.e. at flowering stage and seed formation stage had very positive effects in growth, yield and yield attributing traits of soybean under limited irrigation, Antitranspirant, kaolin@6\% were found to be the most effective that significantly increased the stem height, stem diameter, node number, number of pods, number of seeds per plant, weight of 1000 seeds, seed yield, biological yield and harvest index and most importantly it tremendously increased the yield of soybean by diminishing the adverse effects of water stress (Javan et al., 2013). Higher seed yield, stover yield and biological yield were recorded by the combined application of mulch and antitranspirant, sodium carbonate @5\% while the maximum harvest index, available nitrogen and available phosphorus were enhanced by the co- application of mulch and antitranspirant, glycerol @ 5\% in soybean (Jamir et al., 2016). Combined treatment with straw much @5t/ha and antitranspirant helps to combat the water 
stress condition by reducing the moisture deficient conditions and increased the productivity and profitability in soybean. Antitranspirant application with $\mathrm{MgCO}_{3} @$ $5 \%$ results in highest grain yield in North plain and north eastern zone, glycerol @ 5\% in central zone and KNO3 @1\% in southern zone. Moreover, the maximum net returns and benefit cost ratio were recorded with the antitranspirant application of glycerol @5\% and KNO3 @1\% for all the four zones respectively (Billore, 2017). Foliar treatment with antitranspirant, $\mathrm{MgCO}_{3} @ 5 \%$ and $\mathrm{KNO} 3$ @1\% along with wheat residue mulching $@ 5 \mathrm{Mg} / \mathrm{ha}$ in soybean results in tremendous increase in grain yield and yield attributing traits, qualitative characters like protein content, protein yield, oil content, oil yield and improved the rain water use efficiency (RWUE) significantly under moisturestressed rainfed conditions in semi- arid and north Indian plains. This combined treatment also reduced the adverse effects of moisture and heat stress in soybean plants (Dass and Bhattacharyya, 2017). Foliar application of new antitranspirant, FZ significantly increased the water use efficiency (WUE) by $24 \%$, superoxide dismutase activity by $38 \%$, and peroxidase activity in the leaves by $33 \%$ respectively. FZ spray at pod bearing and pod filling stages, three times, augmented the seed yield by $21 \%$, water consumption significantly in soybean under the conditions of locally used irrigation rates in arid region (Ji et al., 2017). Application with bajra straw mulch @5t/ha along with antitranspirant treatment with potassium nitrate @1\% sprayed at $50 \%$ flowering stage, increased the growth vigour, growth rate, dry matter production, number of pods, higher yield of soybean and in turn provided maximum benefit cost ratio under rainfed conditions (Sanbagavalli et al., 2017). Antitranspirant application with potassium nitrate $\left(\mathrm{KNO}_{3}\right)$ @ $1 \%$ results in increasing the productivity and quality of grains viz., maximum grain yield, straw yield, harvest index, protein content and oil content in soybean significantly. Highest gross return, net return and benefit cost ratio were also recorded by the application of antitranspirant, $\mathrm{KNO}_{3} @ 1 \%$ (Singh et al., 2018).

\section{Antitranspirants in sorghum}

Foliar treatment with antitranspirant, phenylmercuric acetate (PMA) @ 360 uM results in increased stomatal resistance up to 20days, reduced transpiration rate and photosynthesis rate in sorghum. The photosynthesis rate were reported to be reduced more than transpiration rate for a short period of time by the application of PMA that produced prolonged effects on stomata (Sij et al., 1972). Endogenous compounds in sorghum crop were reported to be capable of inducing stomatal closure, often said to be antitranspirants. Under the water deficient or stress conditions in sorghum, a number of naturally occurring antitranspirant was known to be activated such as ABA were active as the amount of stress increased and another one called as trans- farnesol, it induced stomatal closure when applied to the isolated epidermis of Commelina (Ogunkanmi et al., 1974). Under dryland conditions of north- west India, straw mulch and transpiration suppressant agents i.e. antitranspirants namely kaolin and atrazine were reported to reduce water stress thereby by improving the water use efficiency and moisture deficient conditions, increased nitrogen and phosphorus uptake and enhanced the grain yield and contributing traits in sorghum (Raghavulu and Singh, 1982). Mulching with mulches like rice straw mulching effectively controlled the soilsurface evaporation and foliar application with antitranspirants, kaolin and atrazine tremendously increased the grain yield of sorghum under semi- arid conditions on a deep vertisol. These mulches and 
antitranspirants most importantly declined the depletion of soil moisture content and thus improved the water use efficiency (WUE) to a huge extent (De et al., 1983). Application of antitranspirant, $\mathrm{HICO}-11 \mathrm{e} 0 \mathrm{R}$ were recorded to enhance the root length and the shoot length in sorghum and the lower concentration of HICO- 110 R (1g/litre) showed lesser inhibition of the germination percentage and most importantly it favours the seedling growth whereas ABA exhibited more inhibitory effects in the germinating seeds and does not favour seedling growth at all. Overall, both the antitranspirants reduced seed germination percentage in sorghum but ABA showed more inhibitory effects than HICO-110 R (Pawar et al., 2014).

From the previous discussion, it can be concluded that, transpiration suppressant agents i.e. antitranspirants not only reduce the rate of transpiration but alongside they played an immense role in improving the various physiological attributes which involved several vegetative and reproductive parameters, impart disease resistance, improve qualitative characters and most importantly tremendously enhanced the yield and yield contributing traits in cereal crops. Foliar application of antitranspirants such as stomatal closing (PMA 100- 750 uM, potassium chloride 1\%), film forming (chitosan 250 ppm, Nu-film 1\%), reflectance type (Kaolin 3 and 6\%) and growth retardant (cycocel $1000 \mathrm{ppm}$ ) have been found to enhance the different growth, qualitative and yield attributes and also provides highest net return in several cereal crops like wheat, maize, barley, soybean, sorghum respectively.

\section{References}

Abbaspour, N. and Khold, B.B. 2002. Phenyl mercuric acetate (PMA) as an antitranspirant induces salt tolerance in barley and bean plants. Scientific
Information Journal. 4(53): 97-103.

Abdallah, M.M.S., El- Bassiouny, H.M.S. and AbouSeeda, M.A. 2019. Potential role of kaolin or potassium sulfate as antitranspirant on improving physiological, biochemical aspects and yield of wheat plants under different watering regimes. Bulletin of the National Research Centre. 43(1): 134145.

Abdullah, A.S., Aziz, M.M., Siddique, K.H.M. and Flower, K.C. 2015. Film antitranspirants increase yield in drought stressed wheat plants by maintaining high grain number. Agricultural Water Management. 159: 11-18.

Ahmed, Ahmed, Y.M. 2014. Impact of spraying some antitranspirants on fruiting of williams bananas grown under Aswan region conditions. Stem Cell. 5(4): 34-39.

Balwan, Yadav, L.R., Verma, H.P., Kumar, R. and Kumar, S. 2017. Effect of antitranspirants and fertility levels on growth, yield nutrient concentration and uptake in wheat varieties. Annals of Agricultural Research. 38(1): 26-30.

Bayat, S. and Sepehri, A. 2012. Paclobutrazol and salicylic acid application ameliorates the negative effect of water stress on growth and yield of maize plants. Journal of Research in Agricultural Science. 8(2): 127-139.

Billore, S.D. 2017. Enhancing the water stress tolerance in soybean through antitranspirants and mulches. Soybean Research. 15(1): 25-34.

Brahma, R., Janawade, AD. and Palled, Y.B. 2007. Effect of irrigation schedules, mulch and antitranspirant on growth, yield and economics of wheat (cv. DWD-I006). Karnataka Journal of Agricultural Sciences. 20(1): 6-9.

Burondkar, S.S., Sharma, R., Singh, A.S. and Akshay, S.M. 2018. Efficacy of pusa 
hydrogel and chitosan on wheat (Triticum aestivum L.) growth and yield under water deficit condition. Journal of Pharmacognosy \& Phytochemistry. 7(5): 501-505.

Dass, A. and Bhattacharyya, R. 2017. Wheat residue mulch and anti-transpirants improve productivity and quality of rainfed soybean in semi-arid northIndian plains. Field Crops Research. 210: 9-19.

De, B.Y.R., Bheemiah, G., Ramsheshiah, K. and Rao. Y.Y. 1983. Effect of mulches and antitranspirants on the grain yield of sorghum grown under limited irrigations on a deep vertisol. The Journal of Agricultural Science. 100: 159-162.

Desoky, E.S.M., Tohamy, M.R.A., Eisa, G.S.A. and El- Sarkassy, N.M. 2013. Effect of some antitranspirant substances on growth, yield and flag leaf structure of wheat plant (Triticum aestivum L.) grown under water stress conditions. Zagazig Journal of Agricultural Research. 40(2): 1-16.

El- Khawaga, A. S. 2013. Response of grand naine banana plants grown under different soil moisture levels to antitranspirants application. Asian journal of Crop Science. 5: 238-250.

Hellal, F., El- Sayed, S., Gad, A.A, Karim, G.A. and Abdelly, C. 2020. Antitranspirants application for improving the biochemical changes of barley under water stress. Iraqi Journal of Agricultural Sciences. 51(1): 287298.

Jamir, I., Singh, A.K., Jamir, Z., Ao, E. and Prakash, P. 2016. Effect of straw mulch and anti-transpirants on yield and quality of soybean (Glycine max L. Merril). The Bioscan. 11(1): 635-639.

Javan, M., Tajbaksh, M. and Mandoulakani, B.A. 2013. Effect of antitranspirants application on yield and yield components in soybean (Glycine max L.) under limited irrigation. Journal of Applied Biological Sciences. 7(1): 7074.

Ji, S., Tong, L., Li, F., Lu, H., Li, S., Du, T. and $\mathrm{Wu}, \mathrm{Y}$. 2017. Effect of a new antitranspirant on the physiology and water use efficiency of soybean under different irrigation rates in an arid region. Frontiers of Agricultural Science and Engineering. 4(2): 155-164.

Ogunkanmi, A.B., Wellburn, A.R. and Mansfield, T.A. 1974. Detection and preliminary identification of endogenous antitranspirants in waterstressed sorghum plants. Planta. 117: 293-302.

Ouerghi, F., Ben-Hammouda, M., Da- Silva, J.A.T., Albouchi, A., Bouzaien, G., Aluoi, S., Cheikh M'hamed, H. and Nasraoui, B. 2014. The effects of vapor gard on some physiological traits of durum wheat and barley leaves under water stress. Agriculturae Conspectus Scientificus. 79(4): 261-267.

Ouerghi, F., Bouzaien, G., Albouchi, A., BenHammouda, M., Cheikh M'hamed, H., Aloui-Rezgui, S., and Nasraoui, B. 2010. Effects of linseed oil spray on some physiological traits of durum wheat and barley under glasshouse water deficit stress. Tunisian Journal of Plant Protection. 5(1): 1-8.

Pawar, S.G., Pawar, S.S. and Kamble, V.M. 2014. Effect of antitranspirants on the germinating seeds of Sorghum vulgare L. Asian Journal of Multidisciplinary Studies. 2(9): 174-177.

Raghavulu, P. And Singh, S.P. 1982. Effect of mulches and transpiration suppressants on yield, water use efficiency and uptake of nitrogen and phosphorus by sorghum under dry land conditions of north-western India. The Journal of Agricultural Science. 98: 103-108.

Reddy, A.N., Sharma, R. and Pallekonda, 
V.K. 2018. Efficacy of hydrogel on wheat (Triticum aestivum L.) growth and yield under different levels of irrigation. International Journal of Chemical Studies. 6(5): 1576-1579.

Sanbagavalli, S., Vaiyapuri, K. and Marimuthu, S. 2017. Impact of mulching and anti-transpirants on growth and yield of soybean (Glycine $\max$ L. Merril). Advances in Environmental Biology. 11(1): 84-89.

Santakumari, M., Reddy, C.S. and Ramadas, V.S. 1977. Alachlor: a new potent antitranspirant on maize plants. Proceedings of the Indian Academy of Sciences. 86(3): 143-150.

Sij, J.W., Kanemasu, E.T. and Teare, I.D. 1972. Stomatal resistance, net photosynthesis, and transpiration in PMA-treated sorghum: A field study. Crop Science. 12: 733-735.

Singh, A.K., Singh, C.S. and Singh, A.K. 2018. Enhancing productivity and quality of soybean through mulching and antitranspirants in Jharkhand, India. International Journal of Current Microbiology and Applied Sciences 7: 4268-4272.

Sutherland, F. and Walters, D.R. 2002. Effect of the film- forming polymers on infection of barley with the powdery mildew fungus, Blumeria graminis $\mathrm{f}$. sp. hordei. European Journal of Plant Pathology. 108: 385- 389.
Ulameer, Q.Q.A.B.D. and Ahmed, S.A.B.D. 2018. Antitranspirant role in improving the morphological growth traits of maize plants subjected to water stress. Research on Crops. 19(4):593-603.

Walters, D.R. 1992. The effects of three filmforming polymers, with and without a polyamine biosynthesis inhibitor, on powdery mildew infection of barley seedlings. Annals of Applied Biology. 120: 41-46.

Yang, W., Guo, S., Li, P., Song, R. and Yu J. 2019a. Foliar antitranspirant and soil superabsorbent hydrogel affect photosynthetic gas exchange and water use efficiency of maize grown under low rainfall conditions. The Journal of the Science of Food and Agriculture. 99: 350-359.

Yang, W., Li, P., Guo, S., Song, R. and Yu, J. 2019b. Co-application of soil superabsorbent polymer and foliar fulvic acid to increase tolerance to water deficit maize: photosynthesis, water parameters, and proline. Chilean Journal of Agricultural Research. 79(3): 435-446.

Zhang, X., Liu, X., Shao, L., Sun, H. and Chen, S. 2016. Improving winter wheat performance by foliar spray of ABA and FA under water deficit conditions. Journal of Plant Growth Regulators. 35: 83-96.

\section{How to cite this article:}

Vishal Guleria and Shweta. 2020. Antitranspirants: An Effective Approach to Mitigate the Stress in Field Crops. Int.J.Curr.Microbiol.App.Sci. 9(05): 1671-1678. doi: https://doi.org/10.20546/ijcmas.2020.905.188 